Acta Theriologica, Suppl. 5: 135-153, 1998.

PL ISSN 0001-7051

\title{
Remarks on body growth and phenotypes in Asian elephant Elephas maximus
}

\author{
Fred KURT and Janak C. KUMARASINGHE
}

\begin{abstract}
Kurt F. and Kumarasinghe J. C. 1998. Remarks on body growth and phenotypes in Asian elephant Elephas maximus. [In: Ecological genetics in mammals III. G. B. Hartl and J. Markowski, eds]. Acta Theriologica, Suppl. 5: 135-153.

Body growth, expressed as shoulder height and body weight, is compared between 3 captive populations of Elephas maximus Linnaeus, 1758 from Southeast Asia (Thailand and Myanmar), Sri Lanka and 4 European zoos. Under optimal nutritional conditions Asian elephant bulls invest in shoulder height, females in storing resources, ie higher relative body weights. A comparison of 5 Sri Lankan phenotypes, defined by the occurence and the growth type of upper incisivi, revealed that the frequencies of certain physical characteristics such as spinal configuration, extent of depigmentation of trunk, temples, ears and shoulders, as well as eye colours are linked to certain types of incisivi. In males 2 different growth types were found: the relatively fast growing tusker or 'etha' reaching maximum body height and weight at a younger age than the tuskless 'aliyas' and 'pussas'. Both types differ significantly as to the extent of optical marks in terms of depigmentated skin patches at the head pole, which seem to represent the role of conspicious hair colours and tufts of polygamous ruminant ungulates in optical communication.

Institut für Haustierkunde, Christian-Albrechts-Universität zu Kiel, Olshausenstraße 40, D-24118 Kiel, Germany (FK); Department of Zoology, University of Colombo, Colombo 3, Sri Lanka (JCK).

Key words: Elephas maximus, phenotypes, sexual dimorphism
\end{abstract}

\section{Introduction}

From the classical Indian Antiquity (eg Trautmann 1982) and the Middle Ages (Abu'l-Fazl' Alami 1927) until the present time (eg Deraniyagala 1955), Asian elephants Elephas maximus Linnaeus, 1758 have been classified into 4 to 8 different casts. These traditional types were characterized by features such as body size, tail length and spinal configuration, length and form of tusks, number and colour of toe nails, colour of eyes, pigmentation of penis, depigmentation and shinings of the grey skin. Rare combinations are still venerated as 'white' elephants, and certain phenotypes considered as auspitious or inauspicious, respectively (Panicker 1996). But the differentiations have also resulted in practical castings, as not all possible phenotypes are suitable in the same manner to carry saddles and heavy loads, to haul timber or to heave logs on vehicles (eg Toke Gale 1974). Since Antiquity certain phenotypes, mainly those with large body 
size, have been assigned to special geographical regions (Trautmann 1982, Panicker 1996). For example, in Sri Lanka this concept has lead to the definition of subspecies (Deraniyagala 1955), which is questionable due to genetical considerations (cf Hartl et al. 1995b, 1996) as well as to practical experience vith elephants kept under different managment systems (Kurt and Pucher 1997). The efforts of the Asian Elephant Specialist Group of the IUCN to integrate a relatively large captive population of some 15000 captive elephants (Santiapillai and Jackson 1990 ) in its conservation programs are paralleled by a revival of studies on physical characteristics and morphometry of Asian elephant (eg Wemmer and Krishnamurthy 1992, Godagama 1996). But many physical features are compared with shoulder height and body weight, ie exactly with those two characteristics which seem to be strongly variable according to prevailing ecological conditions. Therefore some relations between living conditions and shoulder height and body weight, respectively, will be presented in 3 populations from Southeast Asia (Thailand and Myanmar), Sri Lanka and 4 European zoos.

It can be expected that physical features like the number of fully developed toes, manifested in visible nails, or the presence or abscence of upper incisivi have a predominant hereditary component. Upper incisivi can be enlarged (tusks, in males), rudimentarily present as so called tushes (in males and females) or completely absent (in males and females). Concerning these configurations of incisivi (I), a maximum of 5 phenotypes (I-types) can be distinguished in a population of elephants. These phenotypes are well known in traditional elephant lore, but no informations are available on other characteristics linked to different I-types. These may be either physical features like shoulder height and body weight, tail length, extent of depigmentation, eye colour and ear form, or profiles in body growth. For example, if certain I-types differ in the rate of body growth, different socio-ecological roles could be suspected, as it is also indicated by different strategies of tuskers and tuskless males in search and preparation of food (F. Kurt, unpubl.). A definition of phenotypes may also serve as baseline for future genetical studies on different I-types and their population genetic significance, so far only delt with in models (Kurt et al. 1995, Tiedemann and Kurt 1995). Data on the 5 different I-types stem from captive Sri Lankan elephants, studied by the senior author since 1967 .

\section{Material and methods}

Three populations are distinguished: (1) Timber elephants from Myanmar living under extensive management in forest areas, where they find their own food and meet with tame and wild-living conspecifics when not working. Some $95 \%$ of their measurements stem from captive born animals of either sex. (2) Privately owned elephants from Sri Lanka, which are intensively kept, ie fettered when not at work and fed by man, and used for hauling, parades or tourism. Some $97 \%$ of the measurements stem from anmials of either sex captured in the wild. (3) Female elephants from 4 European zoos. The two Asian populations stem from autochtonous sources. In some $60 \%$ of zoo elephants, countries of orgin are not known (Haufellner et al. 1993), but animals from Sri Lanka and Myanmar 
are present in the sample. In the Sri Lankan population 5 phenotypes (or I-types) have been distinguished according to growth forms and presence of upper incisivi: In males: (1) tusk-bearing 'ethas'; (2) tush-bearing 'aliyas', (3) tusk- and tushless 'pussas'. In females: (4) tush-bearing 'etinnas' and (5) tushless 'alidenas'.

Shoulder height $(\mathrm{S}$; in $\mathrm{cm}$ ) is the vertical distance between the ground and the highest point of the scapula in a standing animal. Altogether, $834 \mathrm{~S}$-values from 750 animals were collected. Thorax circumference or chest girth (TC; in $\mathrm{cm}$ ) is measured immediately behind the forelegs by wrapping the tape around the torso. A total of 293 TC-values are included in the study. Forefoot circumferences were measured in 170 animals. A total of 177 tail lengths were measured from the highest point of the anal folds to the tip. Biten

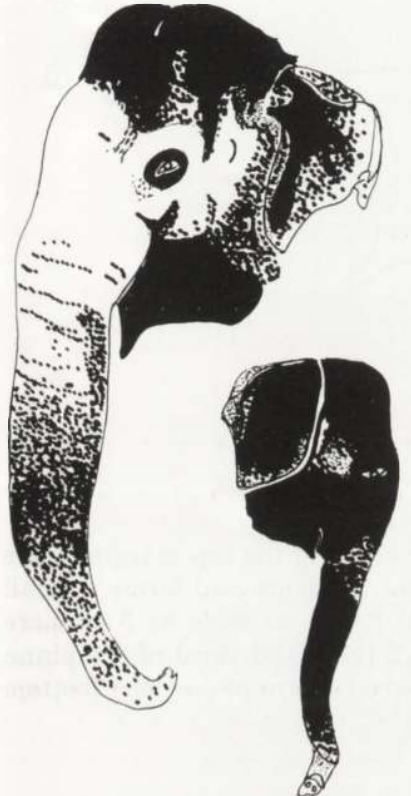

Fig. 1. Extent of depigmentation in an adult (top left) and a juvenile (bottom right) Sri Lankan elephant. In the adult animal depigmentations are extreme on trunk, temples and ears, and mark conspiciously the eye and the opening of the temporal gland. off tails were not considered. Kinked tails were not considered as a special form of tail, as this characteristic is a product of biting by a conspecific or an accident during or short after birth. Body weight is given in $\mathrm{kg}$. Elephants were weighed at heavy-weight - weighbridges. When shoulder height and thorax circumference of an animal with unknown effective body weight were known, body weight was estimated according to the following formulas: for males - weight $(\mathrm{kg})=0,93 \mathrm{TC}^{2} \mathrm{~S} / 10000$; for females - weight $=0,98 \mathrm{TC}^{2} \mathrm{~S} / 10000$. Both formulas are the best known methods to estimate body weight with average deviations of $5-6 \%$ from the actual value (Kurt and Nettasinghe 1968, Kurt and Hartl 1995, Kurt and Pucher 1997). A total 230 measurements of effective body weight from 191 animals and 156 calculated body weights from 155 animals were included in the study. For a closer study on the 5 I-types of Sri Lankan elephants 3 different forms of spinal configurations have been distinguished according to Evans (1910): (1) 'Flat' back - the back line is horizontal without knobs. (2) 'Broken' back - the back line is generally vertical or sloping down from front to tail but shows one or more conspicious knobs. (3) Sloping back - the backline is knobless and follows a slightly rounded sloping line from shoulder to tail base. Spinal configurations have been noted in 305 Sri Lankan elephants. The extent of depigmentation on trunk, temples, ears, and shoulders of 125 Sri Lankan elephants $\geq 15$ years old was described using the following classification: 0 - absent, 1 - depigmentation covers up to $25 \%$ of the area concerned, $2-25-50 \%, 3-50-75 \%, 4-$ more than $75 \%$. Depigmentation stemming from chaining or other wounds inflicted by man were not considered. Eyes and the opening of the temporal gland may be accentuated by more or less complete circles of depigmentated skin (Fig. 1). The extent of this accentuation was described as the extent of depigmentation of the trunk, temples, ears and shoulders, ranging from 0 to 4 .

The upper edge of the ear was classified into 4 forms (Fig. 2): (1) no fold along the top margin of the ear pinna; (2) fold is not wider than a finger; (3) fold is as wide as 1 or 2 fingers and forms a small thin distal triangle, which hangs down when ears are not moved; (4) fold is as wide as 3 or more fingers and forms a conspiciously large distal triangle. In type 1 and 2 the distal third of the pinna can be folded in- or outwards. Three forms of the ear lobes were distinguished (Fig. 2): (1) round, (2) vertically long, (3) more or less horizontally long. Ear forms were recorded in 170 Sri Lankan elephants. Four forms of tail tufts were considered in 160 Sri Lankan elephants: (1) the long bristles are organized in egg shape and a line of bristles growing on the ventral part of the tail above the tuft; 


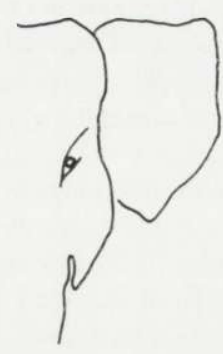

2

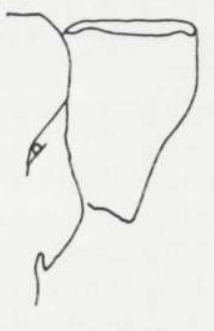

3

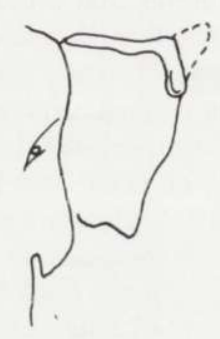

4

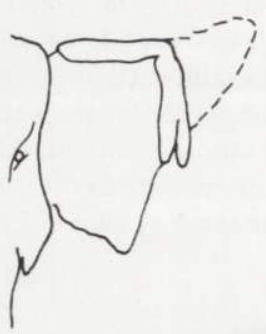

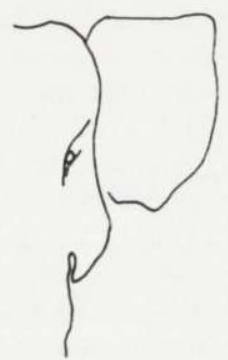

1

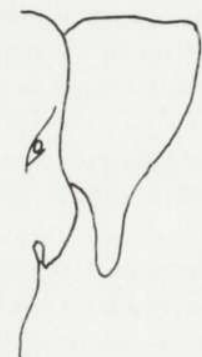

2

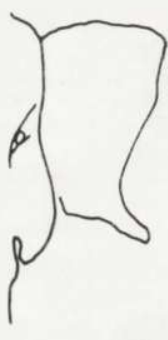

3

Fig. 2. Different forms of the upper edge of the ear (top row): (1) no fold along the top margin of the ear pinna, (2) fold is not wider as a finger, (3) fold is as wide as 1 oder 2 fingers and forms a small thin distal triangle, which hangs down when ears are not moved, (4) fold is as wide as 3 or more fingers and forms a conspiciously large distal triangle. In type 1 and 2 the distal third of the pinna can be folded in- or outwards. Three forms of ear lobes were distinguished. Form of ear lobe (bottom row): (1) round, (2) vertically long, (3) more or less horizontally long.

(2) as in (1), but tuft is open on its tip; ( 3 and 4 ) as ( 1 and 2), but hairs often shorter and no hair line on ventral part of tail above tuft; (5) tuft incomplete, consisting of a few hairs only on one side of the tip of the tail. Four eye colours were distinguished: (1) grey, (2) dark brown, (3) light brown, (4) honey. Eye colours were recorded in 238 Sri Lankan elephants. Data from Evans (1910), Burne (1942), Deraniyagala (1955), Toke Gale (1974), Gerbet (1994) and Godagama (1996) were included where appropriate.

\section{Results}

Shoulder heights are given for 113 Sri Lankan males. From 190 bulls from Myanmar and Thailand 211 measurements of shoulder height were available (Fig. 3 ). In both groups bulls of about 20 years of age reach a shoulder height of some $220 \mathrm{~cm}$. At a higher age, Sri Lankan males grow taller, reaching a mean shoulder height of $265 \pm 17 \mathrm{~cm}$ (mean $\pm \mathrm{SD}, n=16$ ) between 31 and 40 years of age, ie 10 $\mathrm{cm}$ more than bulls of the same age from Thailand and Myanmar $(255 \pm 15 \mathrm{~cm}$, $n=4$ ). Sri Lankan bulls older than 40 years show a mean shoulder height of 262 


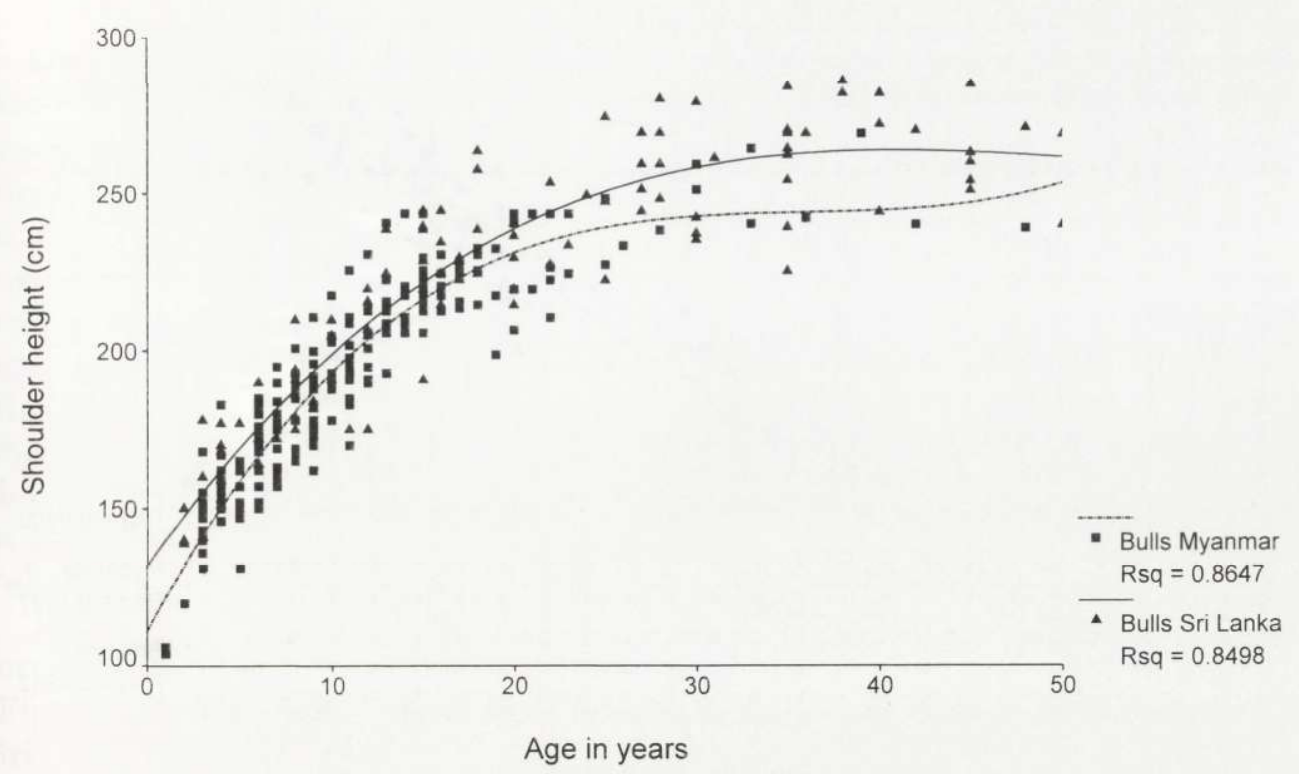

Fig. 3. Growth of shoulder height in Asian elephant bulls, based on 113 measurements from Sri Lanka and 211 measurements from Myanmar and Thailand. In addition to our own measurements data from Evans (1910), Burne (1942), Deraniyagala (1955), Toke Gale (1974) and Gerbet (1994) were included in the study.

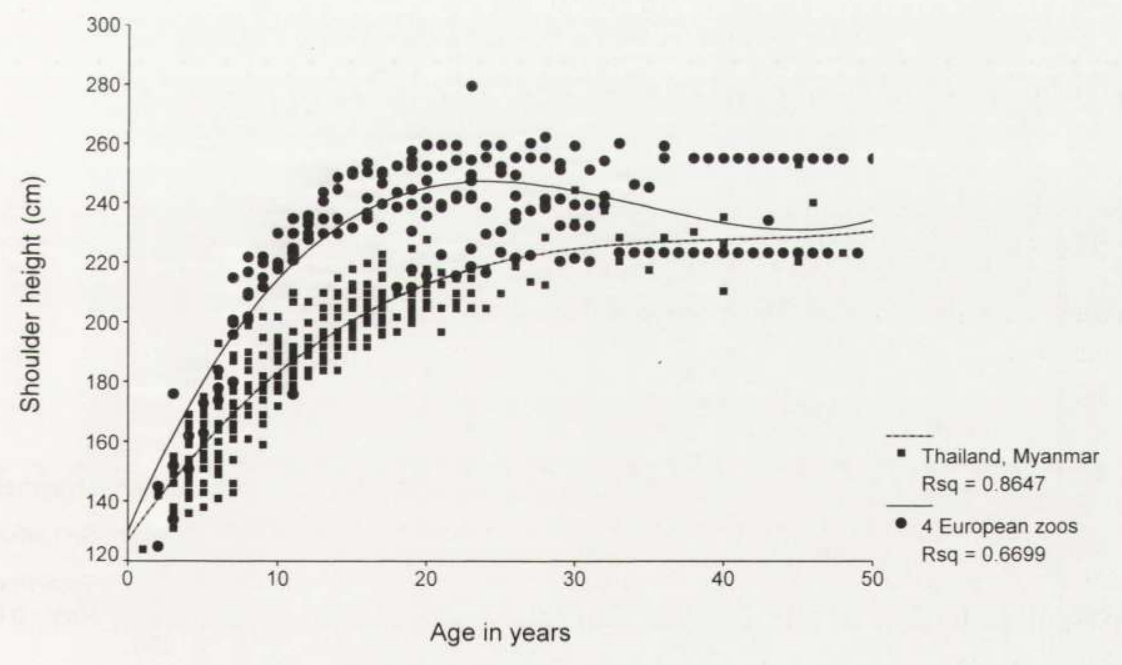

Fig. 4. Growth of shoulder height in female Asian elephants, based on 181 measurements from Thailand and Myanmar, and 159 measurements from 4 Western zoos. In addition to our own measurements data from Evans (1910), Burne (1942), Deraniyagala (1955), Toke Gale (1974) and Gerbet (1994) were included in the study. 


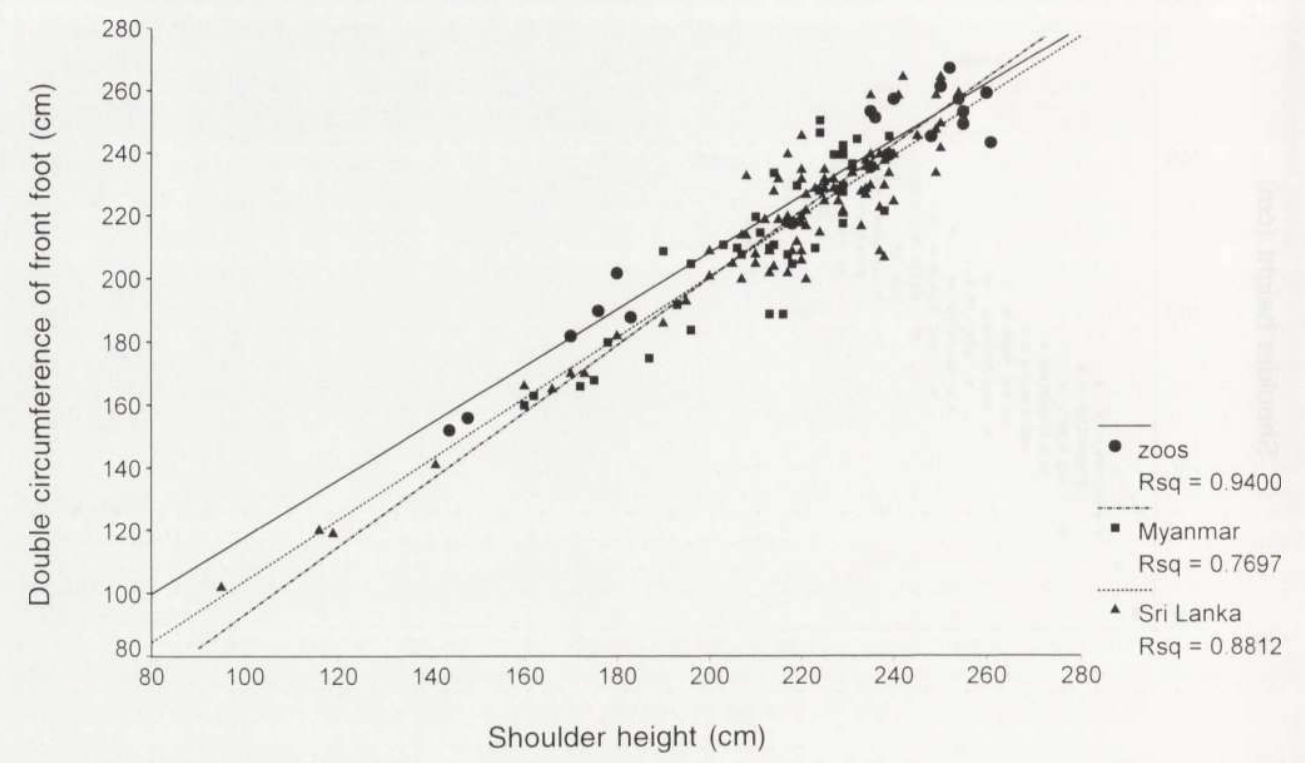

Fig. 5. Relation of shoulder height and the sum of circumferences of the left and the right forefoot in female Asian elephants from Sri Lanka, Thailand, Myanmar and European zoos.

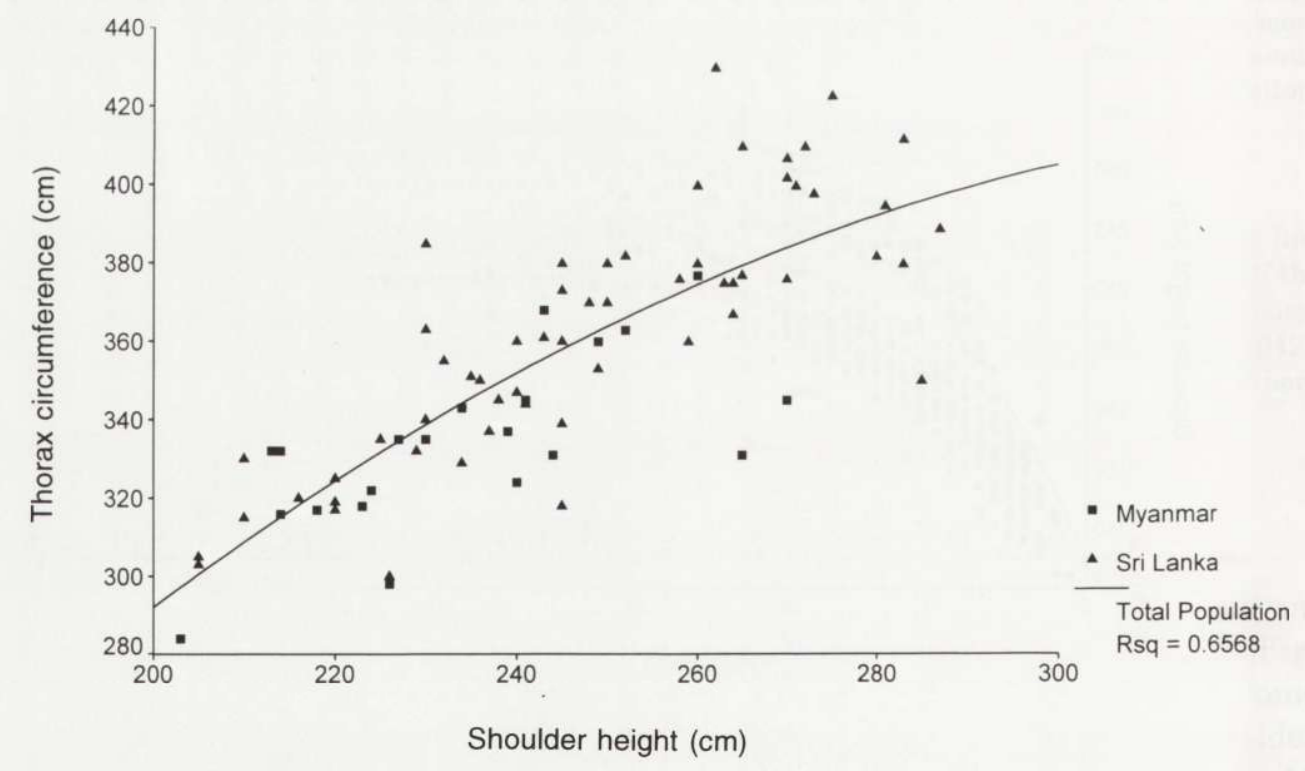

Fig. 6. Relation between shoulder height and thorax circumference in Asian elephant bulls from Sri Lanka, Thailand and Myanmar. 
$\pm 15 \mathrm{~cm}(n=15)$, but two bulls from Myanmar only $240 \mathrm{~cm}$. A total of 181 measurements of shoulder height from 152 females from Thailand and Myanmar were compared with 170 measurements from Sri Lanka. Furthermore, 159 measurements of 125 different females from zoos were available (Fig. 4). Already at an age between 11 and 15 years, zoo kept females $(241 \pm 13 \mathrm{~cm}, n=29)$ are significantly taller than those from Thailand and Myanmar (208 $\pm 9 \mathrm{~cm}, n=52)$, and Sri Lanka ( $221 \pm 14 \mathrm{~cm}, n=22)(p<0.0001)$, but Sri Lankan females of this age group are still taller than those from Thailand and Myanmar $(p=0.0001$; Mann-Whitney $U$ - Wilcoxon Rank Sum $W$ Test). In animals older than 30 years shoulder heights in the 3 samples become more equal, and in age classes higher than 40 years, females from Thailand and Myanmar show a mean shoulder height of $236 \pm 11 \mathrm{~cm}(n=8)$. In Sri Lankan and zoo kept females the corresponding values read $235 \pm 11 \mathrm{~cm}$ and $237 \pm 16 \mathrm{~cm}$, respectively.

In all Asian elephants shoulder height equals twice the circumference of one forefoot or the sum of the circumferences of both the right and the left forefoot (Fig. 5). But only in males, kept under various living conditions in Myanmar and Sri Lanka, shoulder height correlates in a more or less linear manner with thorax circumference (Fig. 6). A total of 77 thorax measurements were available from Sri Lankan, and 42 from Thai and Myanma males. In the range of 240 to $260 \mathrm{~cm}$ shoulder height, 18 Sri Lankan males have a mean thorax circumference of 364 $\pm 19 \mathrm{~cm}$, ie insignificantly larger than the mean thorax circumference of $352 \pm 18$ $\mathrm{cm}$ of 8 males from Thailand and Myanmar. Thorax mesaurements of 109 Sri

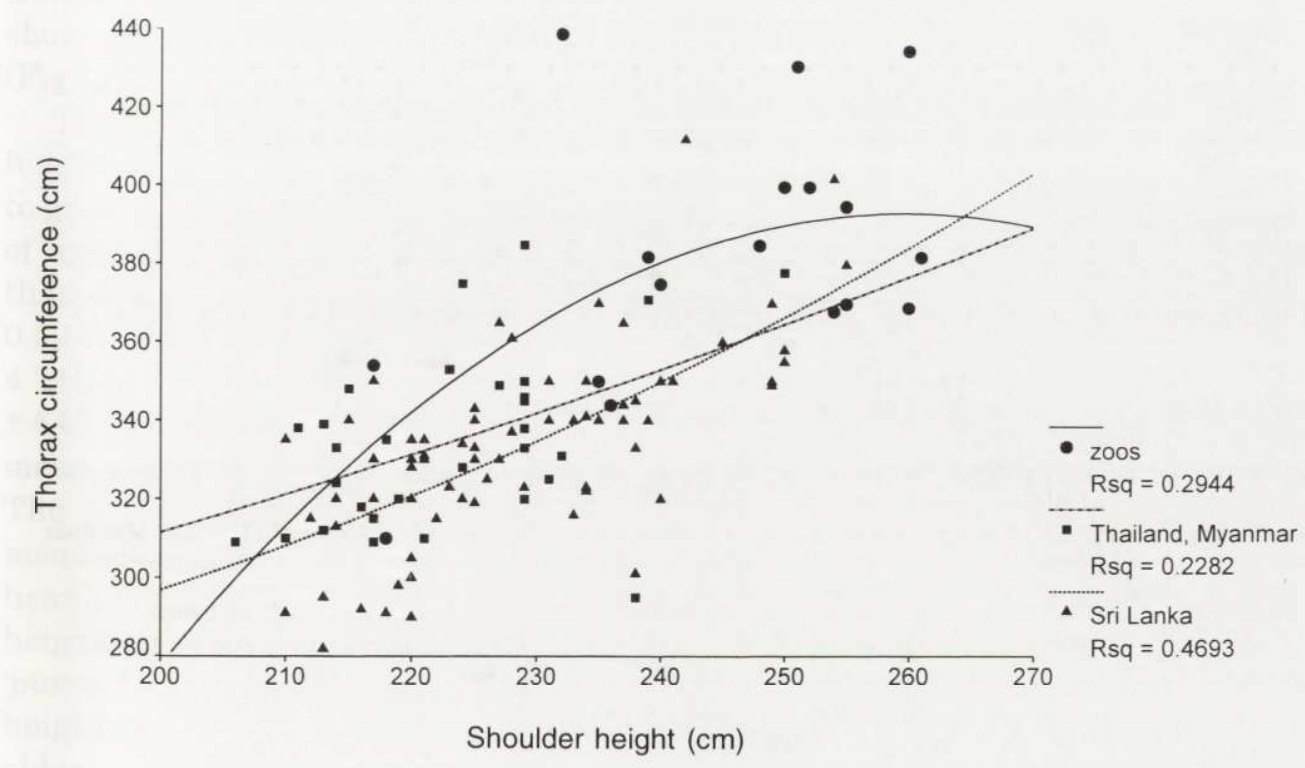

Fig. 7. Relation between shoulder height and thorax circumference in female Asian elephants from Sri Lanka, Thailand, Myanmar and 4 European zoos. 


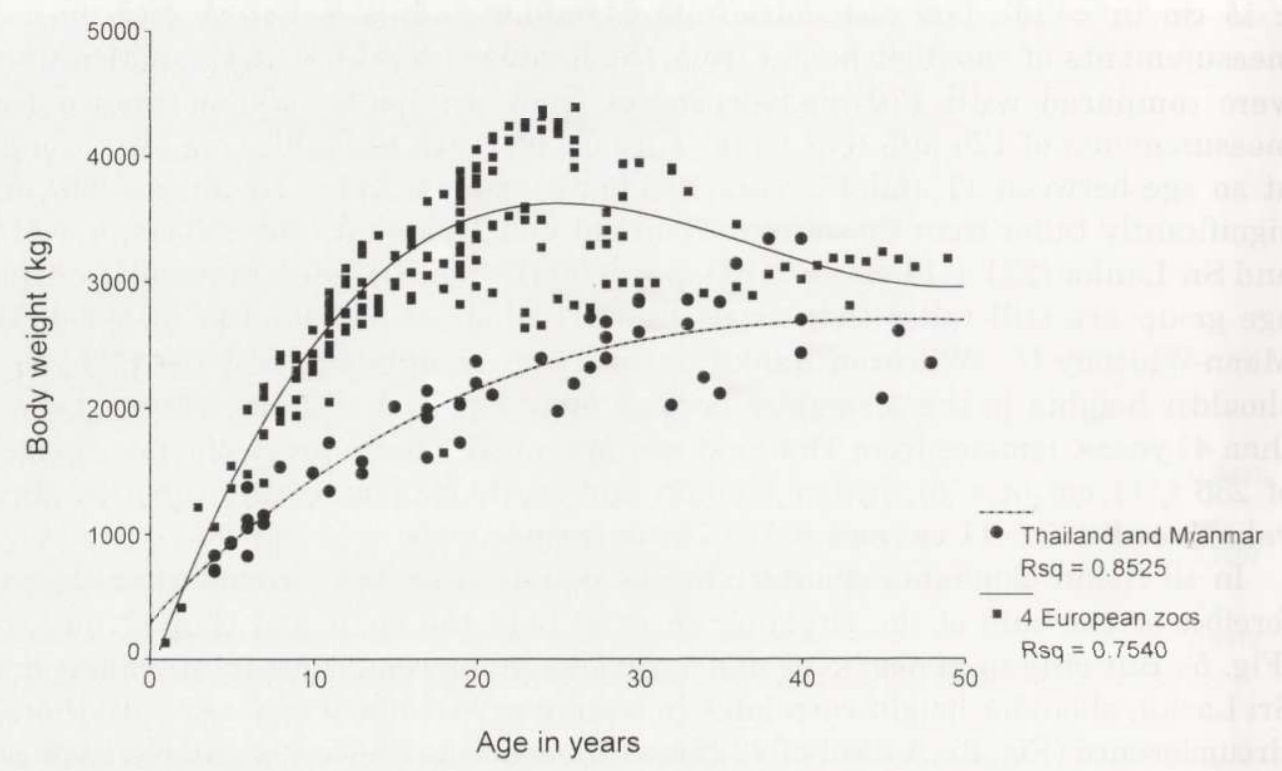

Fig. 8. Growth of body weight in female elephants from Thailand and Myanmar (59 measuements) and European zoos (224 measurements).

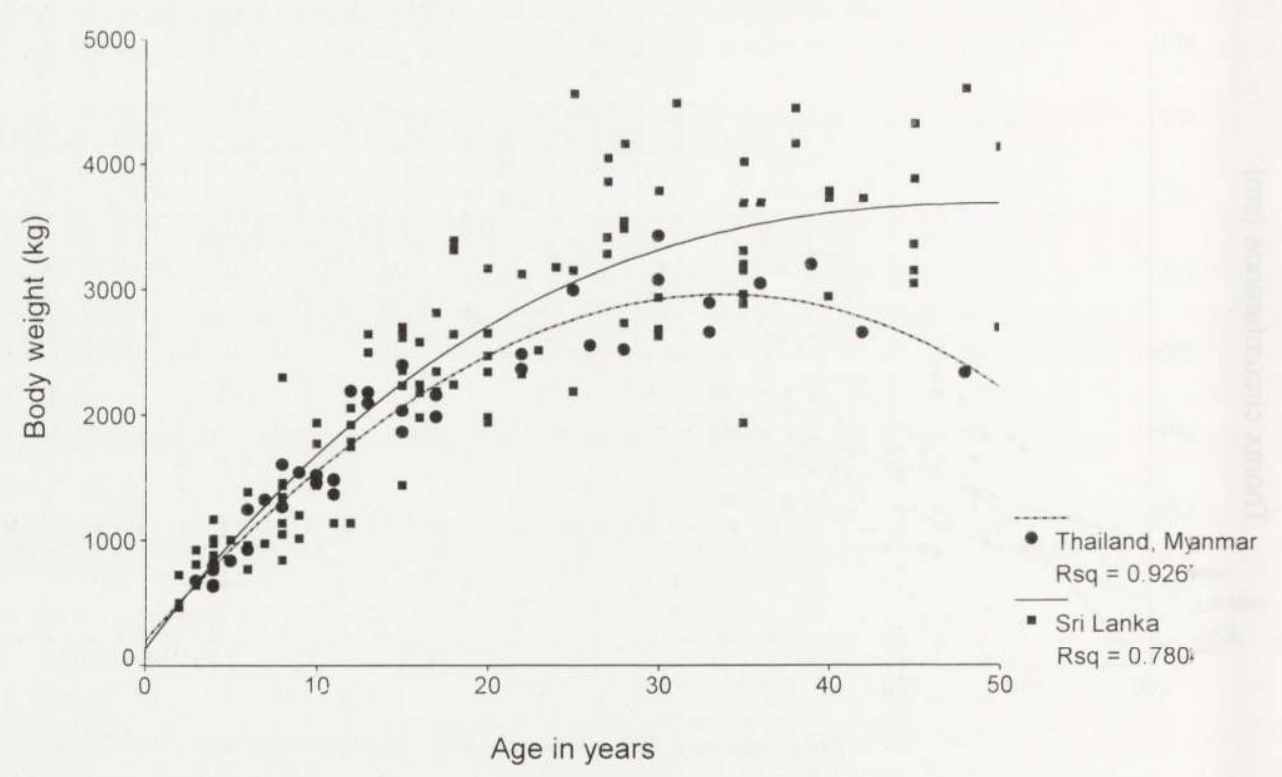

Fig. 9. Growth of body weight in Asian elephant bulls from Sri Lanka, Thailand and Myannar. 
Lankan, 39 Thai and Myanma as well as from 26 females kept in zoos were available (Fig. 7). In females the relation between shoulder height and thorax circumference follows an exponential function, indicating that it depends on living conditions. In the range from 220 to $240 \mathrm{~cm}$ shoulder height, mean thorax circumference of 46 Sri Lankan and 14 Thai and Myanma females amounts to 332 \pm 17 and $342 \pm 24 \mathrm{~cm}$, respectively, but in 6 females from zoos the mean is 373 $\pm 36 \mathrm{~cm}$, ie significantly taller than thorax circumference of Sri Lankan ( $p=$ $0.0007)$, and Thai and Myanma females ( $p=0.0321$; Mann-Whitney $U-$ Wilcoxon Rank Sum $W$ Test). This finding indicates that zoo kept females of the same shoulder height as females living in traditional Asian establishments are more bulky than the latter. This difference is best expressed in body weight. A comparison between 224 body weights of 201 females from zoos and 59 females from Thailand and Myanmar indicates the first shoot up at an age of some five years to reach a climax at the age of some 25 years, with peaks of more than 4 tons, and then fall down to reach after 40 years almost the relatively slow growing curve of the females from Southeast Asian timber camps (Fig. 8). Among 4 age classes covering 10 years, respectively, between 11 and 50 years, the differences are significant ( $p \geq 0.01$; Mann-Whitney $U-$ Wilcoxon Rank Sum $W$ Test). Body weights of Sri Lankan females are more or less intermediate and read $1986 \pm 541$ $\mathrm{kg}(n=28)$ for females between 11 and 20 years, $2593 \pm 298 \mathrm{~kg}(n=16)$ between 21 and 30 years; $2564 \pm 724 \mathrm{~kg}(n=13)$ between 31 and 40 years, and $2588 \pm 475$ $\mathrm{kg}(n=25)$ in females older than 40 years. Comparisons of the growth of body weight between males from Sri Lanka and males from Thailand and Myanmar show that after the age of 30 years the first ones grow heavier due to taller size (Fig. 9).

The 3 I-types of Sri Lankan males were first compared as to growth of shoulder height and body weight (Figs 10 and 11). The tusk-bearing 'ethas' $(n=31)$ seem to grow faster than the the tush-bearing 'aliyas' $(n=75)$. Between 31 and 40 years of age, mean shoulder height of 4 'ethas' is $275 \pm 5 \mathrm{~cm}$ and significantly taller than the mean shoulder height of 12 'aliyas' with a mean of $257 \pm 16 \mathrm{~cm}$ ( $p=$ 0.0247; Mann-Whitney $U$ - Wilcoxon Rank Sum $W$ Test). The mean weight of the 4 'ethas' between 31 and 40 years is $3800 \pm 111 \mathrm{~kg}$ and that of the 12 'aliyas' 3232 $\pm 641(p=0.0687)$. In bulls older than 40 years the mean shoulder height and the mean body weight of 8 'ethas' read $254 \pm 13 \mathrm{~cm}$ and $3302 \pm 430 \mathrm{~kg}$, respectively. The corresponding values for 6 'aliyas' are $264 \pm 14 \mathrm{~cm}$ and $3618 \pm 538 \mathrm{~kg}$. That means that 'aliyas' grow slightly taller and heavier than 'ethas'. The tallest and heaviest bulls are the tusk- and tushless 'pussas' $(n=12)$. The mean shoulder height of 2 'pussas' between 31 and 40 years old is $285 \pm 3 \mathrm{~cm}$, and that of 4 'pussas' older than 40 years is $285 \pm 19 \mathrm{~cm}$, ie significantly larger than the shoulder height of 'aliyas' within the same age classes and significantly larger than in 'ethas' older than 40 years ( $p=0.0136$; Mann-Whitney $U$ - Wilcoxon Rank Sum $W$ Test). Body weight of 'pussas' between 31 and 40 years of age is $4324 \pm 202 \mathrm{~kg}$, and that in specimens older than 40 years is $4589 \pm 451 \mathrm{~kg}$. Similar differences in shoulder 


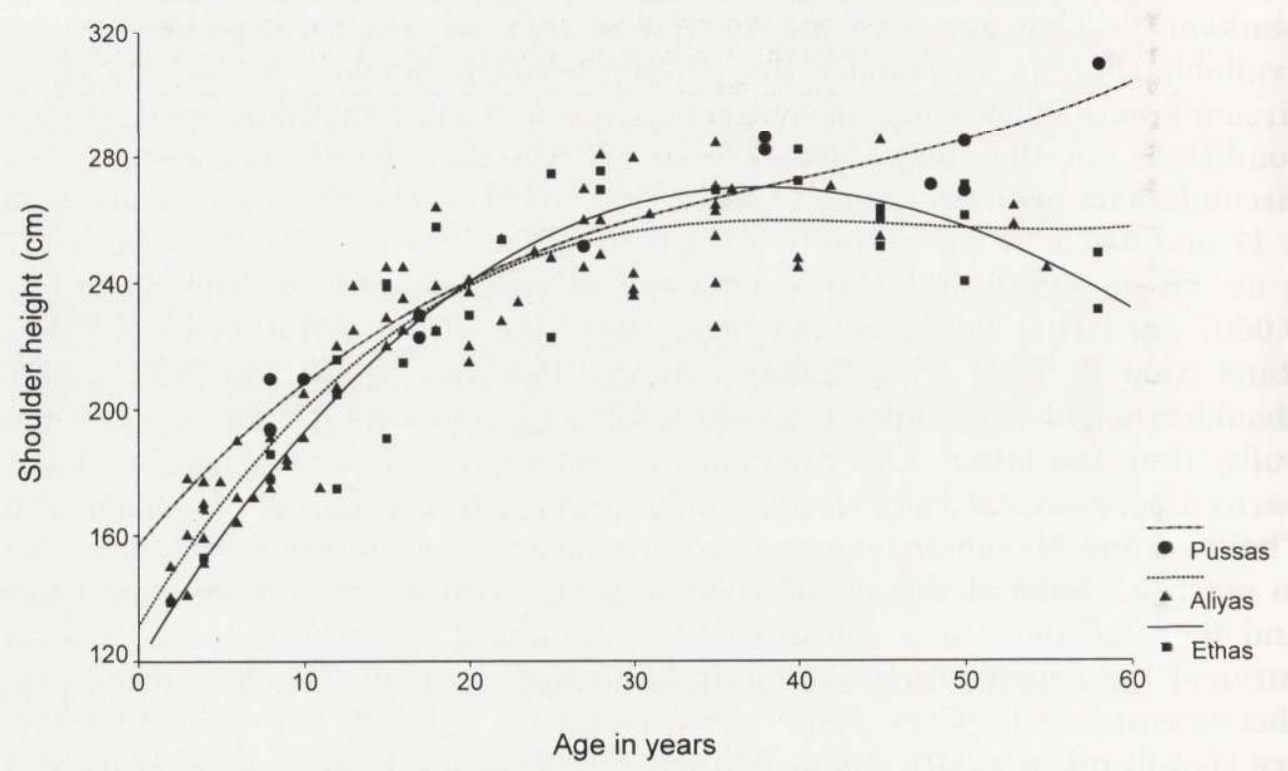

Fig. 10. Growth of shoulder height in 3 I-types of Sri Lankan elephant bulls.

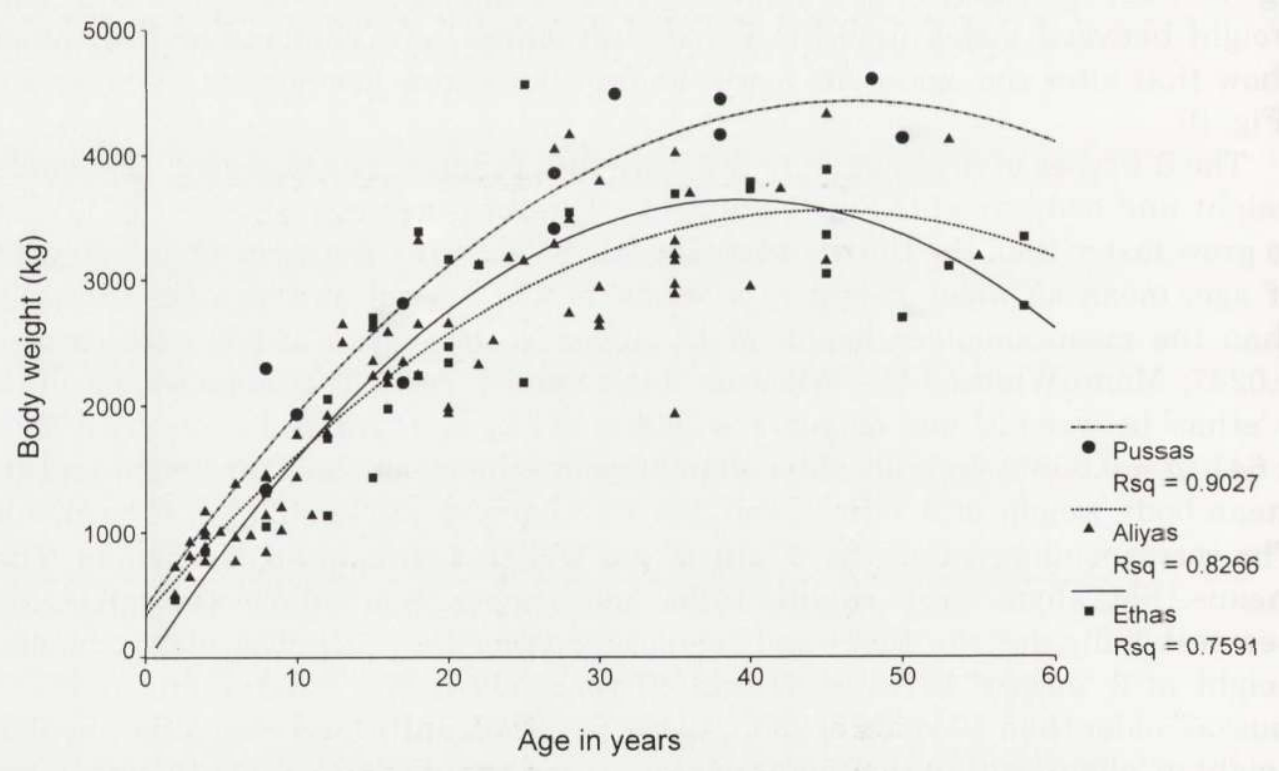

Fig. 11. Growth of body weight in 3 I-types of Sri Lankan bulls. 
height and body weight were not found in a comparison of the 2 I-types in Sri Lankan females, the tush-bearing 'etinnas' and the tushless 'alidenas', respectively.

A comparison of the 5 I-types of Sri Lankan elephants it revealed that 'flat' backs are significantly more common in females $(35.2 \%)$ than in males $(19.2 \%)$ whereas sloping backs are more rare in the former than in the latter $(7.5 \%, 19.2 \%$; Table 1). But there is also a significant difference in the frequency of spinal configurations within males. Sloping backs are more often found in 'ethas' than

Table 1. Comparison of different I-types with different spinal configurations. The difference between all males and all females, and the difference between 'ethas' and 'aliyas' are significant $\left(\chi^{2}=15.21\right.$, $p<0.001 ; 17.58, p<0.001$ ). Data from Godagama (1996) were included.

\begin{tabular}{lccrr}
\hline & 'Flat' back (\%) & 'Broken' back (\%) & 'Sloping' back (\%) & Total (\%) \\
\hline \multicolumn{5}{c}{ Males } \\
1. 'Ethas' & $6(22.2)$ & $9(33.3)$ & $12(44.4)$ & $27(99.9)$ \\
2. 'Aliyas' & $18(17.3)$ & $74(71.2)$ & $12(11.5)$ & $104(100.0)$ \\
3. 'Pussas' & $4(26.7)$ & $7(46.7)$ & $4(26.7)$ & $15(100.1)$ \\
4. All males & $28(19.2)$ & $90(61.6)$ & $28(19.2)$ & $146(100.0)$ \\
& & Females & & \\
5. 'Ethinnas' & $28(36.4)$ & $44(57.1)$ & $5(6.5)$ & $77(100.0)$ \\
6. 'Alidenas' & $28(34.1)$ & $47(57.3)$ & $7(8.5)$ & $82(99.9)$ \\
7. All females & $56(35.2)$ & $91(57.2)$ & $12(7.5)$ & $159(99.9)$ \\
\hline
\end{tabular}

Table 2. Extent of depigmentation on trunk, ears, temples and shoulders of different I-types in Sri Lankan elephants. The amount of depigmentation for each area has been ranked in classes 0-4 (see text for an explanation). The minimum extent of depigmentation for one animal could be 0 , the maximum 16. Significant differences were found between 'ethinnas' and 'alidenas' in all three age groups investigated: $5 \mathrm{~A} / 6 \mathrm{~A}: p=0.019 ; 5 \mathrm{~B} / 6 \mathrm{~B}: p=0,050 ; 5 \mathrm{C} / 6 \mathrm{C}: p=0.046$ (Mann-Whitney $U-$ Wilcoxon Rank Sum $W$ Test).

\begin{tabular}{|c|c|c|c|c|c|c|c|c|c|}
\hline \multirow{3}{*}{ Type } & \multicolumn{9}{|c|}{ Age groups in years } \\
\hline & \multicolumn{3}{|c|}{ A: $15-24$} & \multicolumn{3}{|c|}{ B: $25-40$} & \multicolumn{3}{|c|}{$C: \geq 40$} \\
\hline & Mean & SD & $n$ & Mean & SD & $n$ & Mean & SD & $n$ \\
\hline \multicolumn{10}{|c|}{ Males } \\
\hline 1. 'Ethas' & 4.75 & 1.71 & 4 & 7.0 & 2.92 & 5 & 9.67 & 1.63 & 6 \\
\hline 2. 'Aliyas' & 4.72 & 2.10 & 11 & 9.64 & 2.15 & 22 & 12.3 & 3.20 & 4 \\
\hline 3. 'Pussas' & 6.00 & - & 1 & 10.0 & 5.29 & 3 & 12.0 & 1.00 & 3 \\
\hline 4. All males & 4.81 & 1.90 & 16 & 9.29 & 2.71 & 30 & 11.0 & 2.45 & 13 \\
\hline \multicolumn{10}{|c|}{ Females } \\
\hline 5. 'Ethinnas' & 8.71 & 2.93 & 7 & 10.0 & 3.12 & 9 & 10.5 & 3.18 & 12 \\
\hline 6. 'Alidenas' & 4.42 & 1.83 & 14 & 7.53 & 2.59 & 15 & 7.33 & 3.20 & 9 \\
\hline 7. All females & 5.86 & 3.00 & 21 & 8.45 & 2.92 & 24 & 9.14 & 3.50 & 21 \\
\hline
\end{tabular}


Table 3. Degree of accentuation of eyes and openings of the temporal gland in Sri Lankan elephants older than 20 years. The degree has been estimated for each animal and could range from 0 to 4 (see text for an explanation). In males eyes are significantly more accentuated by depigmentation than in females $(p=0.002)$. Between 'ethas' and 'aliyas' the difference in depigmentation is hardly significant $(p=0.042)$, but 'pussas' have a significantly more prominent depigmentation around their eyes than 'ethas' $(p=0.013)$. No significant difference in depigmentation of the opening of the temporal gland was found between males and females. But in 'ethas' the extent of depigmentation is significantly smaller than in 'aliyas' $(p=0.031)$ and 'pussas' $(p=0.029)$ (Mann-Whitney $U-$ Wilcoxon Rank Sum $W$ Test).

\begin{tabular}{|c|c|c|c|c|c|c|c|c|c|c|c|c|}
\hline \multirow[t]{2}{*}{ Type } & \multicolumn{6}{|c|}{ A: Degree of accentuation of eyes } & \multicolumn{6}{|c|}{$\begin{array}{l}\text { B: Degree of accentuation } \\
\text { of openings of temporal gland }\end{array}$} \\
\hline & 0 & 1 & 2 & 3 & 4 & $n$ & 0 & 1 & 2 & 3 & 4 & $n$ \\
\hline \multicolumn{13}{|c|}{ Males } \\
\hline 1. 'Ethas' & 6 & 1 & 1 & 2 & - & 10 & 2 & 2 & 3 & 2 & 1 & 10 \\
\hline 2. 'Aliyas' & 3 & 6 & 5 & 7 & 2 & 23 & - & 1 & 8 & 9 & 5 & 23 \\
\hline 3. 'Pussas' & - & 1 & 1 & 2 & 1 & 5 & - & - & - & 4 & 1 & 5 \\
\hline 4. All males & 9 & 8 & 7 & 11 & 3 & 38 & 2 & 3 & 11 & 15 & 7 & 38 \\
\hline \multicolumn{13}{|c|}{ Females } \\
\hline 5. 'Ethinnas' & 6 & 10 & 2 & - & 1 & 19 & - & 1 & 9 & 5 & 4 & 19 \\
\hline 6. 'Alidenas' & 14 & 6 & 3 & 2 & 1 & 26 & - & 5 & 13 & 6 & 2 & 26 \\
\hline 7. All females & 20 & 16 & 5 & 2 & 2 & 45 & - & 6 & 22 & 11 & 6 & 45 \\
\hline
\end{tabular}

in 'aliyas', which have more often 'flat' backs. In all 5 I-types the extent of depigmentation of trunk, ears, temples and shoulders increases with age; and 'ethinnas' are significantly more depigmentated than 'alidenas' (Table 2). In males, eyes are significantly more accentuated by depigmentation than in females. In 'ethas' this characteristic is significantly less pronounced than in 'aliyas' and 'pussas'. As to the degree of depigmentation of the opening of the temporal gland, however, no significant difference was found between males and females. But in 'ethas' the accentuation is significantly less prominent than in 'aliyas' and 'pussas' (Table 3).

The form of upper ear edges changes with age and weight. Foldless edges (form 1) are mainly found in young animals, form 3 and 4 correspond with old age and heavy weights. Among different forms of ear edge, pairwise comparisons revealed a stronger statistical correlation with weight than with age (Table 4). The form of the ear lobe correlates neither with sex and age classes nor with body weight. In 74 males and 94 females from Sri Lanka, 57\% of the lower ear tips are round, $24 \%$ are vertically long streched, and $19 \%$ more or less horizontally long strechted. Tail length of 73 Sri Lankan males measures between 68 and $160 \mathrm{~cm}$, with a mean of $117.7 \pm 21.5 \mathrm{~cm}$. In 104 females the mean reads $109.1 \pm 20.0 \mathrm{~cm}$, with extremes of 53-160 cm. Tail length correlates positively with shoulder height. The mean value of relative tail length (tail length/shoulder height) is the same in males (51.8 
Table 4. Mean of ages and body weights of elephants belonging to four different categories with respect to the form of upper ear edges (see text for an explanation). In the correlations with age four significant differences were found between among ear edge types. In the correlations with weight only type 3 and type 4 in females were not significantly different.

\begin{tabular}{|c|c|c|c|c|c|c|c|c|}
\hline \multirow{2}{*}{$\begin{array}{l}\text { Form of upper } \\
\text { ear edge }\end{array}$} & \multicolumn{4}{|c|}{ Age (yrs) } & \multicolumn{4}{|c|}{ Weight (kg) } \\
\hline & Mean & $\mathrm{SD}$ & $n$ & $p$ & Mean & $\mathrm{SD}$ & $n$ & $p$ \\
\hline & & & & Males & & & & \\
\hline 1. & 6.10 & 2.23 & 10 & - & 986.7 & 191.5 & 10 & - \\
\hline 2. & 16.11 & 11.53 & 19 & $1 . / 2 .: 0.023$ & 2040.3 & 983.5 & 19 & 1./2.:0.005 \\
\hline 3. & 23.22 & 14.36 & 18 & 2./3.:0.132 & 2610.0 & 811.2 & 18 & $2 . / 3 .: 0.050$ \\
\hline \multirow[t]{2}{*}{4.} & 32.73 & 13.78 & 30 & $3 . / 4 .: 0.025$ & 3310.5 & 832.5 & 27 & $3 . / 4 .: 0.011$ \\
\hline & & & & Females & & & & \\
\hline 1. & 12.53 & 8.48 & 15 & - & 1340.7 & 540.6 & 15 & - \\
\hline 2. & 15.88 & 10.07 & 17 & $1 . / 2 .: 0.374$ & 1819.1 & 604.3 & 15 & 1./2.:0.022 \\
\hline 3. & 26.19 & 16.27 & 26 & 2./3.:0.028 & 2346.1 & 706.8 & 26 & 2./3.:0.024 \\
\hline 4. & 37.23 & 14.49 & 35 & $3 . / 4 .: 0.006$ & 2454.2 & 531.4 & 35 & $3 . / 4 .: 0.516$ \\
\hline
\end{tabular}

$\pm 5.0 \%, \min -40 \%, \max -65 \%)$ as in females $(51.5 \pm 6.1 \%, \min -32 \%, \max -$ $68 \%$ ). The 4 forms of tail tufts correlate neither with age nor with sex or I-types. In 238 Sri Lankan elephants (116 males, 122 females), 19 (8.0\%) have grey, 30 (12.6\%) dark brown, $142(59.7 \%)$ light brown and 47 (19.7\%) honey coloured eyes. A significant difference was found between 'ethas' and tuskless males. In 18 $(81.2 \%)$ of 22 'ethas' eyes are honey coloured, but this characteristic is found in only $50(53.2 \%)$ of all tuskless bulls studied $\left(\chi^{2}=8.19, p<0.05\right)$. Out of a sample of 1337 elephants from Myanmar only $11(0.8 \%)$ had 20 toe nails or 5 nails on each foot; 1119 (83.7\%) had 18 nails, 5 on each forefoot, and 4 on each of the hind foot; $16(1.2 \%)$ had 17 nails, 1 on 1 forefoot and 4 on each of the remaining feet; $191(14.3 \%)$ had 16 nails, with 4 nails on each foot (Evans 1910, Toke Gale 1974). In a sample of 313 Sri Lankan elephants $1(0.3 \%)$ had 20 nails, $299(95.5 \%)$ 18, $1(0.3 \%) 17$ and $12(3.8 \%) 16$ nails (Deraniyagala 1954, Godagama 1996, this study). The occurrence of aberrations in the number of nails is significantly higher in Myanmar $(16.4 \%)$ than in Sri Lanka $(4.5 \%)\left(\chi^{2}=29.37, p<0.001\right)$.

\section{Discussion}

The following four questions are discussed: (1) Which features distinguished in the present study are related to the keeping system? (2) Which ones can be assigned to other physical conditions (eg climate) of the overall environment? (3) Which ones are linked with the 5 I-types? (4) Are there explanations for particular linkages? The form and extent of the tail tuft, which may be considered a rather 
weak age criterion in free-ranging elephants (Kurt 1992), depend from food and mainly skin care by man in captive elephants (cf Hediger 1990 for zoo elephants). But also body size is influenced by the keeping system: Regression curves of shoulder height versus body weight indicate in general older animals to be slightly smaller and lighter. In zoo kept females this reduction is so extreme that it carnot be explained by physiological and anatomical processes in old age alone, but rather by a higher mortality of obese animals due to heart insufficiency and diseases of overstressed locomotory organs (eg Ruthe 1961, Salzert 1976). Data presented in this study indicate that growth curves of height and weight in females tend to show similar values at the age of 40 years and older. This probably indicates the existence of an ideal maximum weight, and may be due to the fact that only females with a certain body configuration reach an old age. Body weight of an animal is associated with many features of physiology, ecology, and life history (Petters 1983, Schmidt-Nielson 1984), and is also an indicator of overall physical condition. Hence it is an important parameter used in making informed decis.ons concerning the suitability of specific husbandry regimes (Terranova and Coffman 1997). As in primates (eg Schaaf and Stuart 1983) also in the Asian elephant tody weight has been identified as a factor of reproductive performance. Gestation period and neonate weight are positively correlated with relative body weight (kody weight/shoulder height) of the mothers. The rate of still births is positively correlated with obesity of females, and obese females have shorter reproductive periods in their overall life span than wild-living ones (Kurt and Hartl 1995, Kurt and Khyne U Mar 1996). Extremely low relative weights, however, are indicative of the condition of a female of being unfit for reproduction (cf Khyne U Mar $e^{\ddagger}$ al. 1997). Biometrical studies on captive, mainly zoo kept female elephants, are paramount for assessing animal welfare and reproduction success. Measurements of thorax circumference, shoulder height and/or circumference of forefeet are easily obtained, and a simple method for estimating body weight from these data is available (Kurt and Hartl 1995, Kurt and Pucher 1997). But data collected in notoriously obese zoo elephants should be compared to findings from elephants living in their home countries, as overweight is otherwise not realised and considered as natural (eg Fischer et al. 1993).

Animals with extreme body weights living in tropical climates face themoregulatory problems, which, among other features, in African savanna elephants are solved by enlarged ears with dense nets of subcutaneous blood vessels (eg Shoshani 1991). In Asian elephants, relationships between temperature of the environment and the rate of bouts of ear flapping were reported (McKay 1973). The present findings show that the occurence of more or less enlarged folds on the upper edge of the ear correlates better with body weight than with age. This indicates that the distal triangle of thin, extremely depigmentated skin, which is well supplied with blood, may have a thermoregulatory function. It is exposed and fully expanded during ear flapping and hangs folded down when ears are not moved. 
In wild-living elephants shoulder height is considered as a valid age criterion (McKay 1973, Kurt 1974a, 1992, Sukumar 1989), but in many subadult and adult captive elephants shoulder height hardly correlates with age. First of all it reflects living conditions and individual life history. Female calves growing up with their mothers grow faster, taller and heavier than orphaned females (Kurt 1998a, 1998b, in press). South Indian timber elephants born in captivity or caught at an age of less than 10 years show a reduced growth of shoulder height in both sexes, and of body weight in males as compared to wild-living elephants or elephants caught as subadults and adults (Sukumar et al. 1988). This fact is shown in the comparison of mainly captive born animals from camps in Thailand and Myanmar with mainly wild captured ones from Sri Lanka. A reason for reduced growth may be distress from capturing, taming, training and work as well as qualitatively and quantitatively insufficient food (Sukumar 1989). All these factors lead to a more or less pronounced lack of a secondary growth spurt during first pregnancies. In zoos these restraints are absent, and in many sterile zoo kept females extreme growth in height and weight is recorded in the age between 10 and 25 years, when first pregnancies take place in wild-living elephants (Sukumar 1989). In males, growth of shoulder height may be influenced by living conditions but not growth of weight. Hence, for maximizing fitness, Asian elephants display the same tendencies as to body growth as other large polygamous ungulates: Under optimum nutritional conditions males invest in body size and females in storing resources (see Geist 1987, for an overview). Body size may reflect the ability of bulls to find, procure, and process forage resources, and can thus serve as an index of the resources procuring abilities of a male. In any case, female choice favours the tallest bulls (in musth), and shoulder height covaries with reproduction success in wild-living as well as in captive Asian elephants (Kurt 1992, 1995). In social encounters, males in musth, ie those with the highest breeding potential at the moment, rise conspiously head and thorax to demonstrate their body size. Neonate elephants are extreme follower types (eg Lent 1974) as it is typical for offsprings of highly mobile large ungulates. They grow rapidly, and mothers must have the ability to spare relatively more resources from their own growth and maintenance in favour of neonatal growth and the production of milk rich in solids.

The comparisons of growth profiles of male I-types indicate that the tusk-bearing 'ethas' grow faster and reach maximum shoulder height and body weight at a younger age than tuskless males. In cervids 2 phenotypes concerning body and antler growth have been distinguished and characterized by genetic markers (Hartl et al. 1991, 1995a). Studies on behaviour and ecology of several ungulates lead to the assumption that fast growing phenotypes tend to disperse and slow growing ones to spend a more sedentary life ( $\mathrm{cf}$ Kurt 1991, for overview). The hypothesis that tuskers represent rather the dispersal type and tuskless bulls the maintenance type is backed by findings from ecological and ethological studies on wild-living Asian elephants: Female-offspring groups concentrate in areas of secondary growth, rich in appropriate food and open water. Males that are not in 
musth live at the periphery of these core areas, often in primary forests or dry areas of secondary growth, where open water is scarce or absent and feeding activities of bulls could be also responsible for creating new core areas rich in secondary growth (Kurt 1974a, b). Due to their tusks, 'ethas' are better equiped than tuskless bulls to tackle problems of procuring food from woody vegetation and digging for shallow ground water (F. Kurt, in prep.). In any case, different I-types seem to play different social and ecological roles in the population, as they can be characterized by the frequencies of certain spinal configurations and patterns of depigmentation, ie features which may function as optical signals.

So far sexual dimorphism in Proboscidae has been described mainly in terms of tusks and tusk-like structures, body size or the musth period in males. This study proves that sex dimorphism may be apparent also in body form. For example, in bulls the spinal configuration tends to be more often sloping down from shoulder to tail and this phenomenon is most common in 'ethas'. Sloping backs underline and exaggerate body size optically. But sex dimorphism is also underlined by depigmentation. In Asian elephant, the relatively rare hairs probably serve as curve feelers and grids to hold wet mud and leaves to cool the body by evaporation and to protect the skin from sun. Depigmentated skin patches seem to play the role of conspicious hair fields and tufts accentuating the head and especially the eye and skin glands in ungulates (Portmann 1948, Geist 1971). Darkness of faces is linked to aggressive behaviour, and white marks seem to be associated with peaceful gregariousness (Hamilton 1973, Kurt 1978). In Asian elephant naturally depigmentated skin patches are concentrated on the head pole. In young animals, depigmentation starts on the trunk tip and base, on the upper distal tip of the ear and the ear lobe. In old animals depigmentation increases, and accentuates predominately eyes, openings of the temporal gland and ears. These parts are also often touched by the trunk tip of the partner in the course of social contacts (Eisenberg et al. 1971, Garai 1992). Although depigmentations can hardly be recognized in feeding or walking elephants, as their bodies are covered with substrate, the bright marks of depigmentation immediately appear after a shower and a bath at water holes, where most social contacts take place (Kurt 1992). The overall extent of depigmentation is similar in males and females, and in both sexes the opening of the temporal gland is accentuated. In females the temporal gland secrets rarely, and if so in context with the end of a mating period and during parturition. In males it is active during the musth period, when temporal glands are swollen and the dark fluid contrasts with the bright depigmentation (cf Sukumar 1989, Kurt 1992). In females eyes are significantly less accentuated than in males and the tusk-bearing 'ethas' show significantly less depigmentated eye fields than tuskless 'aliyas' and 'pussas'. The difference could be explained by different strategies in aggressive encounters. Although tusks are unimportant in direct combats which are carried out by pushing heads, pressing together the inner trunk bases, scratching with tushes and biting, tuskers can easily threaten tuskless bulls by maneuvering the tip of one tusk under the eye of the opponent 
(Kurt 1992), where the conspicous white skin patch might signal peaceful submission. Lengths and forms of tusks as well as patterns of depigmentation vary immensely among individuals and may serve throughout as distinctive optical mark for each elephant.

But not for all significant links between certain physical features and certain I-types explanations could be found. Remaining questions are for example: Why are 'alidenas' less depigmentated than 'ethinnas'? Why are honey coloured eyes in 'ethas' more abundant than in other elephants and why is the opening of their temporal gland less accentuated by depigmentation than in tuskless males? Furthermore, certain characteristics are not at all linked with I-types. Tail length and the form of the ear lobe vary considerably and seem to be hereditary, as members of the same mother families often possess tails with similar relative length and ear lobes of the same shape, a fact already know since the last century (cf Tennent 1861). Also the aberrations in numbers of toe nails is not linked with I-types and no explanation is available for the fact that aberrations are three times more abundant in Myanmar than in Sri Lanka.

Acknowledgements: The authors are very grateful to numerous personalities in Asia and Europe, who in one or the other way helped in collecting the data presented in this paper. In Sri Lanka: Prof Dr W. D. Ratnasooriya (Dept. of Zoology, University of Colombo), Mr K. D. R. N. Wijersinghe (Director of Dehiwala Zoological Gardens and the Pinnawela Elephant Orphanage), Mr F. S. M. Seelarathna and Mr S. K. Ratnayake (Curators of the Pinnawela Elephant Orphanage), Mr Niranjan Wijeyaratne, the Diyawadana Nilame of the Temple of the Tooth in Kandy, Dr A. P. W. Nettasinghe and Mr M. Lockart, members of the former Smithsonian elephant team, who helped in measuring elephants in 1967 as well as a team of students in veterinary sciences and biology from Austria and Germany, who measured Sri Lankan elephants in 1997. In Myanmar: H. E. the Minister of Forestry, Lt. Gen. Chit Swe, and Dr Khyne U Mar of Myanma Timber Enterprise, who gave the permission for measuring timber elephants and Mr H. Pucher, who measured them in 1996. In Europe: Dr H. Frädrich and Mr R. Pankow of the Berlin Zoo, Dr C. Hagenbeck of Carl Hagenbeck's Tierpark in Hamburg; Mr J. Adler of the Münster Zoo, Dr A. Rübel and Mr R. E. Honegger of the Zurich Zoo have provided us with measurements of their elephants.

\section{References}

Abu'l-Fazl' Alami 1927. A' in-i Akbar (H. Blochmann, D. V. Phillot, transl). Asiatic Society of Bengal, Bibliotheka Indica, Calcutta 61: 1-1492.

Burne E. C. 1942. A record of gestation periods and growth of trained Indian elephant calves in the Southern Shan States, Burma. Proceedings of the Zoological Society, London 42: 27-29.

Deraniyagala P. E. P. 1955. Some extinct elephants, their relatives and the two living species. Ceylon National Museums Press, Colombo: 1-161.

Eisenberg J., McKay G. and Jainudeen M. R. 1971. Reproductive behavior of the Asiatic Elefant (Elephas maximus maximus L.). Behaviour 37: 193-225.

Evans G. H. 1910. Elephants and their diseases. Government Printing and Stationary, Rangoon: $1-343$.

Fischer M. T., Houston E. W., O'Sullivan T., Read B. W. and Jackson P. 1993. Selected weights for ungulates and the Asian elephant Elephas maximus at St. Louis Zoo. Int. Zoo Yb. 32: 169-173.

Garai M. E. 1992. Special relationships between female Asian elephants (Elephas maximus) in zoological gardens. Ethology 90: 187-205. 
Geist V. 1971. On the relation of social evolution and dispersal in ungulates during the Pleistocene, with emphasis on the Old World deer and the genus Bison. Quaternary Research 1: 238-315.

Geist V. 1987. On the evolution of optical signals in deer: A preliminary analysis. [In: Biology and Management of the Cervidae. C. M. Wemmer, ed]. Smithsonian Institution Press, Washington: $235-255$.

Gerbet S. 1994. L'élephant de travail en Thailande: Etudes des traditions locales d'élevage, de dressage et de traitement des affection courantes. Dissertation Faculté de Médicine à Université de Nantes: 1-466.

Godagama W. K. 1996. An ethno-zoology of domesticated elephants in Sri Lanka. Master Thesis, University of Colombo, Colombo: 1-241.

Hamilton W. J. III 1973. Life's colour code. McGraw - Hill, New York: 1-320.

Hartl G. B., Klein F., Willing R., Apollonio M. and Lang G. 1995a. Allozymes and the genetics of antler development in red deer (Cervus elaphus). Journal of Zoology, London 237: 83-100.

Hartl G. B., Kurt F., Hemmer W. and Nadlinger K. 1995b. Electrophoretic and chromosomal variation in captive Asian elephants (Elephas maximus). Zoo Biology 14: 87-95.

Hartl G. B., Kurt F., Tiedemann R., Gmeiner C., Nadlinger K., Khyne U Mar and Rübel A. 1996. Population genetics and systematics of Asian elephant (Elephas maximus): A study based on sequence variation at the Cyt $b$ gene of PCR - amplified mitochondrial DNA from hair bulbs. Zeitschrift für Säugetierkunde 61: 285-294.

Hartl G. B., Lang G., Klein F. and Willing R. 1991. Relationships between allozymes, heterozygosity and morphological characters in red deer (Cervus elaphus), and the influence of selective hunting on allele frequency distributions. Heredity 66: 343-350.

Haufellner A., Kurt F., Schilfarth J. and Schweiger G. 1993. Elefanten in Zoo und Zirkus, Dokumentation Teil 1: Europa. (European Elephant Group, eds). Karl Wenschlow, Munich: 1-232.

Hediger H. 1990. Ein Leben mit Tieren. Werd Verlag, Zürich: 1-502.

Khyne U Mar, Kurt F., Thaung Nyut and Aung Myinth 1997. Fortpflanzung bei Arbeitselefanten in Myanmar. [In: Elefant und Mensch. Workshop zur Elefantenhaltung in Zoo und Zirkus. K. Schaller and C. Ziegler, eds]. Zoo Münster: 26-37.

Kurt F. 1974a. Elephants - shapers of the jungle. Image Roche 59: 2-13.

Kurt F. 1974b. Remarks on the social structure and the ecology of the Ceylon elephant in the Yala Nationalpark. [In: The behaviour of ungulates and its relation to managment. V. Geist, F. Walter, eds]. IUCN Publications new Series 24: 618-634.

Kurt F. 1978. Socio-ecological organization and aspects of management in South Asian deer. In Threatened deer, IUCN: 87-108.

Kurt F. 1991. Das Reh in der Kulturlandschaft. Paul Parey, Hamburg und Berlin: 1-284.

Kurt F. 1992. Das Elefantenbuch. Rasch und Röhring Verlag, Hamburg und Zürich: 1-239.

Kurt F. 1995. The preservation of Asian elephants in human care - a comparison between different keeping systems in South Asia and Europe. Animal Research and Development 41: 38-60.

Kurt F. 1998a. Pinnawela Elephant Orphanage - Die grösste Elefantenherde in Menschenobhut. Berichte aus Forschung und Wissenschaft, Schönbrunner Tiergarten-Journal 7(24): 1-11.

Kurt F. 1998b. Captive breeding of the Asian elephant (Elephas maximus) in Asia and in western zoos - A comparison of different management systems. [In: International Seminar on the Conservation of Asian Elephants. R. Sukumar, ed]. Yangon. (in press)

Kurt F. and Hartl G. B. 1995. Asian elephants (Elephas maximus) in captivity - A challenge for zoo biological research. [In: Research and captive propagation. U. Ganslosser, J. K. Hodges and W. Kaumanns, eds]. Filander Verlag, Fürth: 310-326.

Kurt F., Hartl G. B. and Tiedemann R. 1995. Tuskless bulls in Asian elephant (Elephas maximus). History and population genetics of a man-made phenomenon. [In: Ecological genetics in mammals II. G. B. Hartl and J. Markowski, eds]. Acta Theriologica, Suppl. 3: 125-143.

Kurt F. and Khyne U Mar 1996. Neonate mortality in captive Asian elephants (Elephas maximus). Zeitschrift für Säugetierkunde 61: 155-164. 
Kurt F. and Nettasinghe A. W. 1968. Estimation of body weight of the Ceylon elephant (Elephas maximus). Ceylon Journal of Veterinary Sciences 14: 24-28.

Kurt F. and Pucher H. 1997. Körpermasse, Gewicht und Gewichtschätzung bei Asiatischen Elefanten (Elephas maximus). [In: Elefant und Mensch. Workshop zur Elefantenhaltung in Zoo und Zirkus. K. Schaller and C. Ziegler, eds]. Zoo Münster: 13-20.

Lent P. C. 1974. Mother-infant relations in ungulates. [In: The behaviour of ungulates and its relation to management. V. Geist and F. Walter, eds]. IUCN Publ. New Series 24: 14-55.

McKay G. M. 1973. Behaviour and ecology of the Asian elephant in Southeastern Ceylon. Smithsonian Contributions to Zoology 125: 1-113.

Panicker K. C. 1996. Desirable and undesirable traits in elephants. Zoos' Print: 30-31.

Petters R. H. 1983. The ecological implication of body size. Cambridge University Press, Cambridge: $1-241$.

Portmann A. 1948. Die Tiergestalt. Verlag Friedrich Reinhardt, Basel: 1-246.

Ruthe H. 1961. Fussleiden der Elefanten. Wiss. Zeitschr. Humboldt - Univ. Berlin. Math. Nat. Reihe 10: 471-516.

Salzert W. 1976. Elefanten. [In: Zootierkrankheiten. H.-G. Klös and E. M. Lang, eds]. Verlag Paul Parey, Berlin - Hamburg: 133-152.

Santiapillai C. and Jackson P. 1990. The Asian elephant. An action plan for its conservation. IUCN/WWF, Gland: 1-123

Schaaf C. D. and Stuart M. D. 1983. Reproduction of the mongoose lemur in captivity. Zoo Biology 2: $23-38$.

Schmidt-Nielson K. 1984. Scaling: Why is animal size so important? Cambridge University Press, Cambridge: $1-156$.

Shoshani J. 1991. Anatomy and physiology. [In: The illustrated encyclopedia of elephants. G. Rogers and S. Watkinson, eds]. Salamander Books Ltd, London: 30-47.

Sukumar R. 1989. The Asian elephant, ecology and management. Cambridge University Press, Cambridge: $1-251$.

Sukumar R., Joshi N. V. and Krishnamurthy V. 1988. Growth in the Asian elephant. Proceedings of the Indian Academy of Sciences (Animal Sciences) 97: 561-571.

Tennent J. E. 1861. Sketches of the natural history of Ceylon. Longman, Green, Longman, and Roberts, London: 1-500.

Terranova C. J. and Coffman B. S. 1997. Body weight of wild and captive lemurs. Zoo Biology 16: $17-30$.

Tiedemann R. and Kurt F. 1995. A stochastic simulation model for Asian elephant Elephas maximus populations and the inheritance of tusks. [In: Ecological genetics in mammals II. G. B. Hartl and J. Markowski, eds]. Acta Theriologica, Suppl. 3: 111-124.

Toke Gale 1974. Burmese Timber Elephant. Trade Cooperation, Ragoon: 1-162.

Trautmann T. R. 1982. Elephants and the Mauriyas. [In: India: History and Thought. G. Mukerjee, ed]. Subarnarekha Ltd., Calcutta: 254-281.

Wemmer C. and Krishnamurthy V. 1992. Methods for taking standard measurements of live domestic elephants. [In: In the Asian elephant - ecology, biology, diseases, conservation and management. E. G. Silas, M. K. Nair and G. Nirmalan, eds]. Lumiere Printing Works, Trichur: 34-37. 